\title{
Use of External Cephalic Version and Amnioreduction in the Delivery of a Fetal Demise with Macrocephaly Secondary to Massive Intracranial Teratoma
}

\author{
Matthew J. Blitz, MD, MBA ${ }^{1} \quad$ Elizabeth Greeley, MD ${ }^{1} \quad$ Hima Tam Tam, MD ${ }^{1}$ Burton Rochelson, MD ${ }^{1}$ \\ ${ }^{1}$ Division of Maternal-Fetal Medicine, Department of Obstetrics and \\ Gynecology, Hofstra North Shore-LIJ School of Medicine, \\ Manhasset, New York \\ Address for correspondence Matthew J. Blitz, MD, MBA, Department \\ of Obstetrics and Gynecology, Hofstra North Shore-LIJ School of \\ Medicine, North Shore University Hospital, 300 Community Drive, \\ Am J Perinatol Rep 2015;5:e77-e79. \\ 4-Levitt, Manhasset, NY 11030 (e-mail: matthew.blitz@gmail.com).
}

\author{
Abstract \\ Keywords \\ - fetal brain tumor \\ - intracranial teratoma \\ - prenatal diagnosis \\ - external cephalic \\ version \\ - amnioreduction
}

Introduction Congenital intracranial tumors are rare and often incidentally diagnosed on routine ultrasound. We report a case of a fetal demise with a massive intracranial teratoma at 25 weeks of gestation and the management of her delivery in the setting of macrocephaly, breech presentation, and polyhydramnios.

Case A 31-year-old G3P1011 woman at 25 weeks' gestation presented with a recent fetal demise and a fetal intracranial tumor first identified at 16 weeks' gestational age. The patient had declined termination of pregnancy. Biometry was consistent with 24 weeks' gestation, except for a head circumference of $394.4 \mathrm{~mm}$ consistent with 39 weeks' gestation. The fetus was in a breech presentation. An external cephalic version (ECV) was successfully performed under epidural anesthesia and an amnioreduction was then performed to stabilize the fetal position. Immediate induction of labor and vaginal delivery followed.

Discussion ECV and amnioreduction may help facilitate delivery in cases of fetal demise complicated by macrocephaly, malpresentation, and polyhydramnios.

Fetal brain tumors are exceedingly rare, accounting for 0.5 to $1.5 \%$ of all childhood brain tumors, with an estimated incidence of 1.1 to 3.4 per million live births. ${ }^{1}$ Although partially dependent on location and histologic type, they are usually associated with a poor fetal prognosis. Early cesarean delivery or termination before viability, employing destructive operations when appropriate, may help avoid obstetric complications because of the cephalopelvic disproportion. Here, we present a case of a massive immature fetal intracranial teratoma with antenatal cranial perforation and the management of her delivery in the setting of macrocephaly, breech presentation, and polyhydramnios.

received

January 7, 2015 accepted after revision January 23, 2015 published online March 26, 2015

\section{Case Report}

A 31-year-old woman, G3P1011 at 16 weeks' gestational age was found to have a fetus with an intracranial mass on ultrasound. The lesion progressively grew with significant distortion of intracranial skull anatomy at 20 weeks. She was counseled at both visits regarding the dismal prognosis and was offered termination. At $25^{2 / 7}$ weeks' gestational age, she presented for a maternal-fetal medicine consultation regarding the large fetal intracranial mass. Her history was remarkable for a previous first trimester elective termination followed by a term vaginal delivery. At the time of consultation, a fetal demise with hydrops was discovered on

Copyright $\odot 2015$ by Thieme Medical Publishers, Inc., 333 Seventh Avenue, New York, NY 10001, USA. Tel: +1(212) 584-4662.
License terms

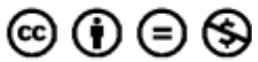

10.1055/s-0035-1547332. ISSN 2157-6998. 
ultrasound. Fetal biometry was consistent with 24 weeks' gestational age based on long bone measurements, but the fetal head circumference was $394.4 \mathrm{~mm}$ consistent with 39 weeks' gestational age. An $8 \times 10 \mathrm{~cm}$ heterogeneous intracranial mass (-Fig. 1) was identified and the fetus was in breech presentation.

Given the high concern for fetal head entrapment during a breech delivery, an external cephalic version (ECV) was attempted but was unsuccessful, likely because of the poor fetal tone and the relatively small fetal torso. Management options that were subsequently considered included another ECV attempt under regional anesthesia, hysterotomy, or dilation and evacuation with cranial destruction. The patient was highly motivated to have a vaginal delivery and wanted to avoid surgery. She was admitted to Labor and Delivery for ECV under epidural anesthesia. Because of the early gestational age, polyhydramnios, and extreme macrocephaly, there was concern that the fetus would return to a breech presentation, even in the setting of a fetal demise. Therefore, an amnioreduction was recommended to assist in maintaining the fetus in a cephalic presentation during induction of labor. A sterile amniocentesis procedure was performed under continuous ultrasound guidance with a 20-gauge needle and approximately $1,200 \mathrm{~mL}$ of murky brown fluid was obtained via suction. Following the version, ultrasound demonstrated a posterior defect in the cranium. It remains unclear whether this defect was present before or as a consequence of the version. Alpha-fetoprotein levels in the amniotic fluid were elevated.

The patient was induced with $200 \mu \mathrm{g}$ misoprostol administered vaginally for two doses 3 hours apart and then started on oxytocin. During delivery, the intracranial mass was propelled through the posterior cranial defect. She ultimately had a vaginal delivery and was discharged home the following morning. The final pathology report described a female fetus (-Fig. 2) with a congenital intracranial immature teratoma completely replacing the brain and hydrops fetalis. The tumor weighed $186 \mathrm{~g}$.

\section{Discussion}

Congenital intracranial tumors are very rare and often incidentally diagnosed on routine second or third trimester ultrasound. They are frequently associated with macrocephaly, hydrocephalus, bulging anterior fontanel, or polyhydramnios. $^{2}$ Teratomas, as presented in this case, are the most common histologic subtype, accounting for between 36 to $62 \%$ of congenital brain tumors; they are most often located supratentorially and are composed of tissue derived from all the following three embryonic germ layers: endoderm, mesoderm, and ectoderm. ${ }^{3,4}$ Further classification, as mature or immature, is based on the degree of tissue differentiation. Rapid, invasive tumor growth that destroys and obliterates normal cerebral and cranial structures is responsible for the poor fetal prognosis. The 1 -year survival rate is less than $10 \%$. Survivors typically have profound developmental delay. ${ }^{3}$ Intrauterine treatment remains an investigational procedure.

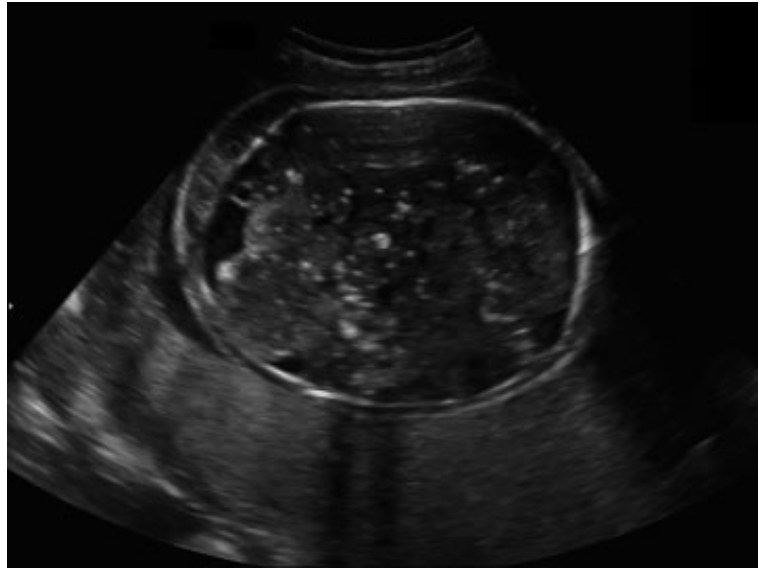

Fig. 1 Ultrasound demonstrating massive intracranial mass at 25 weeks' gestation.

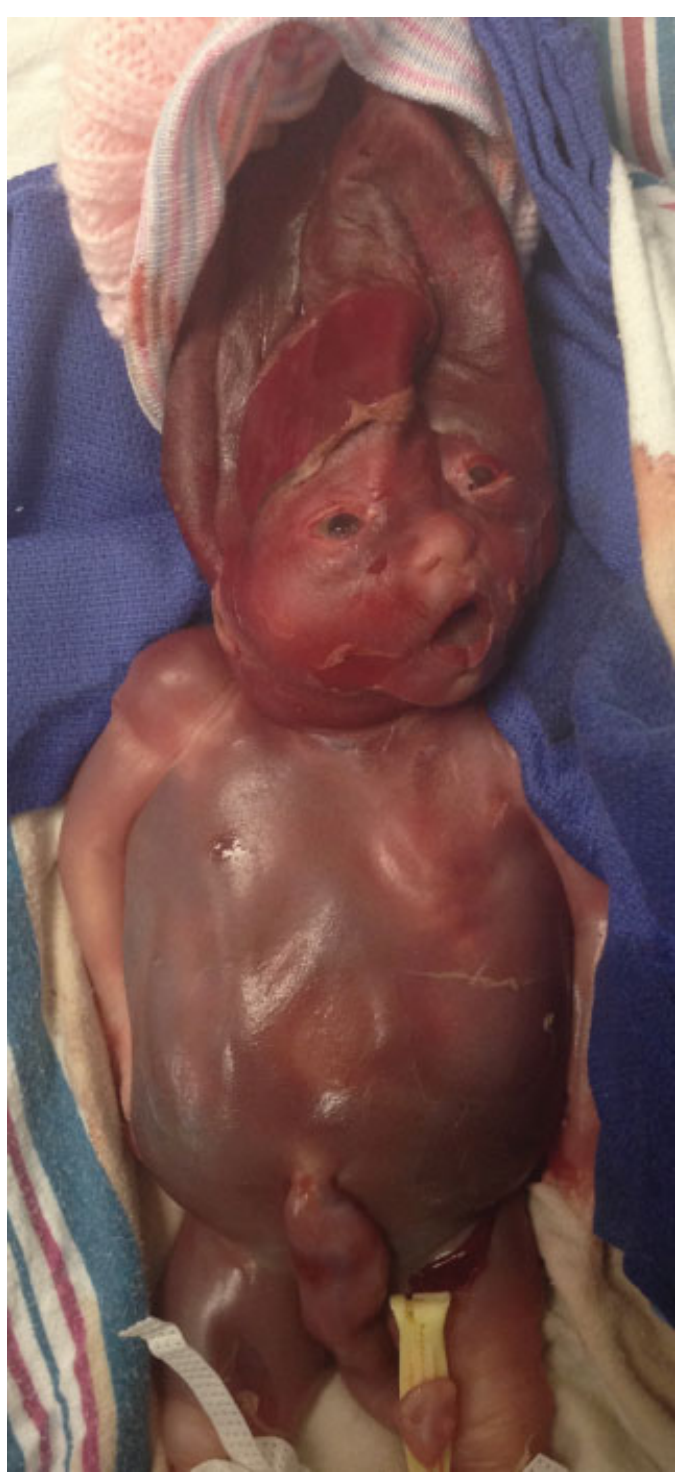

Fig. 2 Macroscopic appearance of the newborn. 
ECV following an intrauterine fetal demise is typically unnecessary. With a live fetus undergoing a vaginal breech delivery, there is an increased risk of head entrapment and other fetal injuries. ${ }^{5}$ In addition, few providers are sufficiently skilled to perform these deliveries. In this clinical scenario, patients are offered an ECV and, if successful, will proceed with spontaneous or induced labor. With a fetal demise in breech presentation, surgical delivery should be avoided if possible given its inherent risks. This case is unusual given the significant fetal head size and the possibility that a breech delivery could also require a destructive procedure such as cephalocentesis or craniotomy to deliver the head. ${ }^{6}$

Decompression amniocentesis has been used in singleton pregnancies complicated by severe and symptomatic polyhydramnios but no randomized trials have evaluated whether it is superior to expectant management. ${ }^{7}$ Amnioreduction following ECV is rarely performed. In this case, because of the polyhydramnios and extreme macrocephaly, we felt that this would optimize the stability of the fetal position until delivery was achieved. To our knowledge, this type of management has not been previously reported.

\section{References}

1 Manoranjan B, Provias JP. Congenital brain tumors: diagnostic pitfalls and therapeutic interventions. J Child Neurol 2011;26(5): 599-614

2 Chien YH, Tsao PN, Lee WT, Peng SF, Yau KI. Congenital intracranial teratoma. Pediatr Neurol 2000;22(1):72-74

3 Koizumi K, Abe E, Kusanagi Y, Ito M. Giant immature intracranial teratoma with antenatal cranial perforation. J Obstet Gynaecol Res 2010;36(6):1252-1255

4 Saada J, Enza-Razavi F, Delahaye S, Martinovic J, Macaleese J, Benachi A. Early second-trimester diagnosis of intracranial teratoma. Ultrasound Obstet Gynecol 2009;33(1):109-111

5 Goffinet F, Carayol M, Foidart JM, et al; PREMODA Study Group. Is planned vaginal delivery for breech presentation at term still an option? Results of an observational prospective survey in France and Belgium. Am J Obstet Gynecol 2006;194(4): 1002-1011

6 Chasen ST, Chervenak FA, McCullough LB. The role of cephalocentesis in modern obstetrics. Am J Obstet Gynecol 2001;185(3): 734-736

7 Dickinson JE, Tjioe YY, Jude E, Kirk D, Franke M, Nathan E. Amnioreduction in the management of polyhydramnios complicating singleton pregnancies. Am J Obstet Gynecol 2014;211(4): 434.e1-434.e7 